\title{
MIRAGENS E PRISMAS: O BARROCO DÁ MOVIMENTO ÀS IMAGENS HERMÉTICAS NA POESIA SUASSUNIANA
}

\author{
Paulo Caldas Neto \\ Graduado em Letras/Língua Portuguesa e \\ Mestre em Literatura Comparada pela Universidade Federal do Rio Grande do Norte \\ paulocaldas31@gmail.com
}

\section{RESUMO}

Este artigo visa a estudar a presença de uma vertente barroca na poesia contemporânea. Nada melhor que a lírica armorial de Ariano Suassuna para servir de investigação a nossas suspeitas. Sendo esse gênero da obra suassuniana tão pouco examinado, provavelmente não se conheça a sua importância para a construção do sentido de sua dramaturgia e de sua prosa de ficção (bem mais conhecidas). A relação desenhada entre a teoria da dobra barroca de Deleuze e os estudos sobre a estética dos Setecentos casou tranqüilamente com a finalidade de se descobrir a essência de todo o hermetismo. Ora o poema armorial é barroco, ora seu conjunto imagético pode até sugerir, fazendo com que o leitor pense que se trata de um esteticismo simbolista, a prova disso está no registro de substantivos concretos com suas letras iniciais maiúsculas. Daí, tem-se, em parte, o movimento da dobra, sempre mutante, oscilador. Na primeira seção, é feito um breve panorama da arte barroca, marcada por suas irregularidades. Na segunda seção, justifica-se o efeito que estas causam: as dobras. A partir delas, as correspondências entre as formas fixas do poema, a heráldica sertaneja e os problemas do Nordeste se completarão perfeitamente.

PALAVRAS-CHAVE: Ariano Suassuna, poema, Barroco, dobra e hermetismo.

\section{ESPEJISMOS Y PRISMAS: EL BARROCO DA MOVIMIENTO A LAS IMAGÉNES HERMÉTICAS EN LA POESÍA SUASUNIANA}

\section{RESUMEN}

Este artículo mira a estudiar la presencia de una vertiente barroca en la poesía contemporanea. Nada mejor que la lírica armonica de Ariano Suassuna para servir de investigación a nuestras sospechas. Siendo ese género de la obra suasuniana tan poco examinado, probablemente no se conozca su importancia para la construcción del sentido de su dramaturgia y de su prosa de ficción (bien más conocidas). La relación dibujada entre la teoría del doblez barroco de Deleuze y los estudios sobre la estética de los Setecientos casó tranquilamente con la finalidad de descubrirse la esencia de todo el hermetismo. O el poema armorial es barroco o su conjunto imaginario incluso puede sugerir, haciendo con que el lector piense que se refiere a un esteticismo simbolista, la prueba de eso está en el registro de sustantivos concretos con sus letras inciciales mayúsculas. De ahí, se tiene, en parte, el movimiento del doblez, siempre mutante, oscilador. En la primera sección, es hecho un breve panorama del arte barroca, señalada por sus irregularidades. En la segunda sección, se justifica el efecto que éstas causan: los doblezes. A partir de ellas, las correspondencias entre las formas fijas del poema, la heráldica campesina y los problemas del noreste se completarán perfectamente.

PALABRAS-LLAVE: Ariano Suasuna, poema, Barroco, doblez y hermetismo. 


\section{MIRAGENS E PRISMAS: O BARROCO DÁ MOVIMENTO ÀS IMAGENS HERMÉTICAS NA POESIA SUASSUNIANA}

\section{INTRODUÇÃO}

Em nível de leituras comparativas, há muito já se chegou a conclusões proeminentes de que o estilo barroco transpõe as fronteiras do academicismo e da apreciação isolada das literaturas nacionais, realizando um comparativismo entre as mesmas. Desse método, extrai-se o intercâmbio de matrizes européias para constatar-se a perpetuação do barroquismo ainda como estética moderna.

O barroco, a princípio, é conhecido pelo conceito de pedra irregular por um simples preconceito de nossa crítica neoclássica, que reagia a tal forma de expressão artística, considerando-a um tabu da linguagem. Esse "mau gosto" nos leva a crer na existência de uma raiz modernista implicitamente em vigor muito antes da primeira alvorada do séc. XX. O interesse em compreendê-la e libertá-la de más interpretações possivelmente nos guie também aos contornos que a desorganizam e a organizam, gerando um movimento de dobras e redobras até obter-se o equilíbrio da idéia. Nos anos de 1887, 1888, com base em formas clássicas do Renascimento, alguns historiadores da arquitetura ocidental, dentre os quais Cornelius Gurlitt, concluíram ser um modo de expressão ostensivo e exagerado, explanando uma apreensão com curvas mais salientes, isto é, formas livres e pitorescas, pouco adoradas pelos apreciadores de traços estéticos bem determinados, lineares do Classicismo (HATZFELD, 1988, p.14). A inconstância da obra barroca é que causa o peso de seu conteúdo e o sentimento de desproporção. É daí que se tem a ânsia e a possibilidade de a forma atingir o infinito, engendrando a sensação de eternidade. E sempre será esse o destino de todo bom trabalho do período dos Setecentos, desde que tenha homens místicos e sonhadores de mundos sublimes e da infinitude destes.

Ainda assim, ao mesmo tempo em que marca o senso perceptivo de quem a contempla, a arte barroca desvenda as confusões e resultados desconfortáveis no intento de se entendê-la melhor, pois o ilusionismo do mundo divide seu espaço com a realidade e há circunstâncias em que esta vence a imaginação. O autêntico contraste do existir e do funcionar na Terra e no Cosmos. Enaltecendo-se a espiritualidade do objeto, consegue-se sobrepô-lo à matéria, e o finito acaba adquirindo a aura de infinitude. Pode-se, com isso, interpretar que o Barroco, em oposição ao Renascimento, cultiva um estilo de profundidade, unidade, complexidade e obscuridade. Isto é: sob a perspectiva do pictórico e de uma profundidade, o múltiplo vira o uno no centro da obra barroca, reunindo toda a filosofia numa relativa obscuridade sem muitos excessos. Será na Espanha, mais especificamente pelas mãos de Velázquez na pintura, que a noção da essência do objeto ocupará maior destaque, suplantando o seu lado ocidental, sem contornos ao primeiro olhar que inspeciona o retratado. Essa nova técnica do pictórico é o ponto de partida para a impressão de longitude, e que de certa maneira prenuncia a arte impressionista do séc. XX e delimita a região dos extremos — o profano e o sagrado. $\mathrm{O}$ transcendental começa a ganhar relevância na metafísica barroca da Espanha, onde deixará sementes.

Enquanto conceito formal e estrutural rumo a uma teoria poética, o Barroco é um estilo imaturo que só desabrocha em terreno espanhol, quando se afasta um pouco do petrarquismo italiano e da poética aristotélica, incorporando a face da Cultura Popular espanhola e promovendo sua independência das outras expressões do barroquismo em 
países como a França, onde conseguiu uma distância do Renascimento. Testemunha-se a maior manifestação de unidade de Deus a partir de trocas entre o espiritual e o corporal, sabendo manter os espaços que cada um ocupa:

Foi Marcel Bataillon que, em 1937, apresentou uma teoria do Barroco mais ampla e que procurou de novo as raízes deste movimento no Concílio de Trento. A fórmula central diz respeito à sua origem: o penoso nascimento de uma ortodoxia, entre 1556 e 1563. Nesta teoria tridentina, a Espanha é ao mesmo tempo sujeito e objeto. É sujeito, principalmente, enquanto este país, em que a cristandade esteve em contacto com os semitas por espaço de séculos, não assimilou o paganismo italiano renascentista, mas, de preferência, uma espécie de espiritualismo de tipo setentrional. Este "erasmismo" tenta manter um equilíbrio instável entre o protestanismo do norte e um Renascimento paganizado. (HATZFELD, 1988, p.23)

Novas correntes despontaram para traduzir as pretensões do Barroco espanhol, todavia, acabaram por cometer alguns equívocos. Tanto o Erasmismo quanto o Inacismo (este defendido por Santo Inácio) seguiram caminhos opostos após o Concílio, porque o primeiro adotava uma posição mais renascentista, sustentando a tese de que o paganismo clássico poderia ser preservado na doutrina cristã até mesmo para ajudá-la a desenvolver-se enquanto saber litúrgico. Ao contrário de tudo isso, o segundo acreditava que os ideais greco-latinos serviram apenas ao ensino do mundanismo, atentando contra o modelo desenvolto, parabólico e loquaz. O Barroquismo necessita da inflexão tal qual meio de atingir o infinito e, assim, essa segunda vertente pareceu mais confiante a um propósito moderno, que chegaria a bater as portas da contemporaneidade. $\mathrm{O}$ comprometimento, talvez, a fim de que se concebessem novos valores a uma cultura nascente durante o período de efervescência artística, deu-se em função de os referidos pensadores, especialmente Erasmo, terem ignorado a necessidade de um movimento metafísico coletivo do espírito de uma nação qual acontecimento espontâneo e não imposto. $\mathrm{O}$ Barroco é sensação, subjetividade; Classicismo é razão, objetividade.

Bataillon, Pfandl, Castro e Guillermo Díaz-Plaja, em 1940, foram infelizes ao distorcerem ainda a contestada arte dos Setecentos, propondo uma definição que exclui a submissão do individual ao coletivo. A justificativa para isso não é muito clara e cai num preconceito ao responsabilizar a Cultura Judaica pela exaltação da infinitude e o desapego ao real. Em outras palavras, a índole do imaginário é rebaixada por esses teóricos, cuja tentativa frustrante de salvar os valores clássicos, ameaçados pelo sucessor Barroquismo, encaixando-os a este, só serviu para levantar novas questões que deram origem a um fidedigno princípio: o culto à beleza do terrível. Aí, ter-se-á fundamento para argumentarse sobre a influência barroca e seu movimento ondulatório da dobra na vida sertaneja brasileira, descrita na lírica de Ariano Suassuna. Por enquanto, ficar-se-á com o debate das teorias do Barroco e os efeitos de suas dobras no espírito humano.

É evidente que nas pesquisas da poética barroca encontram-se, agora, certos princípios que a relacionam à forma e à psicologia nela embutidas. Eles ilustram o embate que o Renascimento provoca, divulgando os traços definidores de ambos os estilos: austeridade em oposição à candura; a complexidade em vez da simplicidade; e a catolicidade representando a ideologia da dimensão espiritual, substituta do materialismo racional. A 
principal herança do Catolicismo espanhol e italiano brilhará na sensualidade, a verdadeira expressão do seu lado transcendental, à que Mario Praz concebe uma simbologia humanista e um resgate do esteticismo grego como aspectos barrocos. Unindo modelos da Antigüidade com os do humanismo, ocasionar-se-á uma perturbação no espírito que terá na metáfora a forma mais expressiva dessa loucura na alma. $\mathrm{O}$ aprendizado que se tira dessa síntese é o de um Barroquismo jamais indagado solitariamente. Há pontos em comum em todas as literaturas européias, desenterrados por instrumentos de comparação teórica. Um deles, o de praxe, diz respeito à semelhança das temáticas e às escolhas da métrica e da estrofe adequadas na poesia; no teatro (área de pouca atuação barroca), o drama é ferramenta de tensão interna para o homem que sofre o trágico conflito entre as fronteiras da razão e do sentimento. Em todos os gêneros (o lírico, o dramático, o narrativo), o gênero também é fator paradoxal, pondo no mesmo lugar dois extremos da consciência humana: a certeza e a dúvida. Sempre são os antagonismos os responsáveis pelas frustrações e pelo equilíbrio abstrato-concreto do texto setecentista que lida com imagens poéticas, representantes dos pólos da Pirâmide existencial, numa esteira de matrizes morais e culturais contrastantes. Não se pode esquecer de que o Renascimento em parte já trazia um ponto de vista do real, voltado para o racional, e tal modo de pensar forneceu as diferenças de ambos os estilos de época.

Numa unidade superior, estão imersas as incompatibilidades que o Barroco agrupa, e os homens precisam retirar deles a dignidade. Aparentemente harmonioso, o universo se constrói com vistas nessa dualidade, oferecida pela grandeza e pelo horror do devir. A procura da paz desejada no meio de toda essa tensão passional infunde uma problemática em torno da fase barroca do séc.XVII por ainda esta estar presa aos padrões do Renascimento. Por isso, os historiadores da literatura européia resolvem classificar o intervalo de tempo anterior ao Barroquismo e posterior à Renascença de Maneirista, essencialmente anticlássico, além de ser uma ocasião menos racionalista e sentimental.

Quando o amanhecer barroco raia, logo após as delimitações de sua natureza poética, sem o risco de confundi-la com o Maneirismo, é que vamos perceber a unidade estética dominando-a. Mas o que seria esse temperamento uno tão acentuado na obra? Qual a representatividade de sua composição ao elo entre o mundo sagrado e o mundo profano antes explícito? São questionamentos que voltam sua atenção a certas feições barrocas e à complexidade e à austeridade das mesmas. A melhor explicação está em seus componentes mínimos: as dobras. Delas, trataremos agora.

\section{NESTE VALE DE DOBRAS}

A constituição da essência do Barroco está em apenas um traço, sua única função operatória. Ele se move ritmamente e, em várias posições até alcançar o infinito, fermentando dobras. Estas não são todas iguais. Há dobras gregas, romanas, góticas, românicas, clássicas que se transformam em curvas e recurvas e seguem duas direções, dois infinitos, que mais parecem dois andares, conforme algumas teorias determinem a critério didático: as redobras da matéria e as dobras na alma. No andar debaixo, a matéria se organiza em gêneros da dobra, até as partes comporem órgãos, que de tão dobrados têm o seu completo desenvolvimento no andar superior, já próximo a Deus. Daí para adiante, a dobra toca o infinito. As múltiplas condições, que elevam a matéria ao sétimo céu, atribuem um novo significado à liberdade da alma, e este passa a adotar estradas menos retilíneas com inclinações bem agudas. Assim, os dois andares se comunicam para que o 
movimento oscilatório entre a parte inferior e superior dessa casa barroca aconteça, e as aberturas logo na base propaguem vibrações. Estas levam as idéias inatas da alma para um espaço mais imponente. Depois, conseguem respirar aliviadas, porque justamente uma grande dobra se encarrega desse deslocamento delas até o paraíso, acolhedor da imagem da salvação.

$\mathrm{Na}$ alegoria dessa residência imaginária, é reparável o vestígio do Barroco ao identificarem-se, dentre outras particularidades, os degraus baixos e curvos, o tratamento da matéria por massas ou agregados e o arredondamento dos ângulos. Lançando mão do presente raciocínio e do resgate do Rococó pela modernidade, faremos aqui umas breves aplicações na poesia contemporânea, sobretudo naquela que tomou ares na Arte Armorial do Nordeste dos anos 70 do século passado. Nosso extrato será a lírica de seu líder, Ariano Suassuna, cuja produção enquanto poeta é pouco conhecida.

Sua carreira literária iniciou-se pelo gênero lírico em 1945. Nessa época, a pedido de seu mestre Tadeu Rocha e do editor Esmaragdo Marroquim, Suassuna escreveria um poema (o título do trabalho viria a ser Noturno) para publicação no Suplemento Literário do Jornal do Commercio do Recife. A partir daí, outros trabalhos brotarariam das páginas do manuscrito do paraibano que depois cursaria Filosofia e Direito em Pernambuco. Para o futuro, Ariano intensificaria seus ensaios como poeta sempre divulgando poesias nos diversos meios de comunicação em massa até reuni-las em livro por volta de 1980. Foi quando apresentou ao público seu primeiro livro, $O$ pasto incendiado, que se divide em duas seções: A taça e $O$ pasto. Pertencente à segunda, está o soneto Ao Cristo Crucificado, cuja epígrafe denuncia uma composição feita de uma leitura de Santa Teresa de Ávila e do poeta Gregório de Mattos:

Se esse Céu, desejado e imerecido, for, Coroa de crimes resgatados, no termo de meus Dias fatigados, pelo Amor, à minh'alma concebido,

sei que este Amor, que é vosso e que, ferido, jaz em meu Peito, cego de pecados, excederá de muito os sons Alados dos Sonhos em que vivo suspendido.

Mas, lembrando o Desterro meu, presente, (se permitido for), na Aventurança talvez eu chore a falta desusada

do tempo em que, contrito e Penitente, achava a própria Culpa grata e mansa por ser de Vós reunida e consolada.

(SUASSUNA, 1999, p.116)

A temática da crucificação e do conflito de sentimentos diante da religiosidade, exposta nesse pequeno conjunto de quadras e tercetos, é importante à percepção do Barroquismo, destacado pelas suas antíteses intensas e coloridas, que são os deslocamentos das dobras debaixo para cima no interior dos andares da casa. O alvo é a investigação pelo equilíbrio e a harmonia do corpo e do espírito. O poeta compara o seu martírio ao de Cristo e, no meio 
dessa metáfora do vazio, deixa clara a fluidez da matéria ao transbordar os seus limites no Cosmos. As horas não têm fim, uma vez que parecem estar presentes, sem nunca terem passado. E aí recupera-se a efemeridade do tempo mítico e seu encaixe no tempo real, instigando a trajetória curvilínea e turbulenta da matéria, que consegue permitir libertar-se da linearidade e de todas as barreiras as quais estava submetida. Esses turbilhões numa textura infinitamente fluida, que é o corpo do Cristo, pode conter um universo de regiões irregulares em que as flutuações de seus sentidos têm um sinal bastante sutil. O eu-lírico do poema em questão insiste em demonstrar essa postura de sua alma sensitiva em confronto com o corpo físico do Messias sempre com uma expressão de dureza e compreensão por acreditar inconscientemente na elasticidade das forças espirituais sobre a carne, ou seja, o material.

As próprias iniciais maiúsculas de algumas palavras, até mesmo as que são gramaticalmente tidas por substantivos abstratos viram substantivos concretos, como se o poeta quisesse aproximar a dimensão do sobrenatural, o mundo mítico, à dimensão do real, o mundo que se vê, que se contempla a olho nu. Se não, vejamos:

\section{Céu/ Coroa/ Dias; Amor/ Peito/ Sonhos; Desterro/ Aventurança/} Culpa

A retomada desses componentes abre a mente para uma reflexão da suposta existência de uma fluidez absoluta e de uma dureza, outrossim, absoluta, isto é, a hipótese atomista e a hipótese cartesiana sob a forma dos corpos finitos. É plena a linguagem dos opostos em relação à flexibilidade e à elasticidade da anatomia humana, porque se, por um lado, as porções desta convergem com coerência numa divisão de dobras, por outro, é necessário que elas não se dissolvam em pontos mínimos no interior do corpo. Tudo isso se dá em função de a matéria possuir molas. Se, assim como o físico de Jesus, todas as qualidades exteriores do homem concentram em si mesmas a mobilidade, então é fundamental que se pense tal fator não só qual a divisão de partes, "mas também da progressividade na aquisição e na perda do movimento, realizando-se, ao mesmo tempo, a convenção da força" (DELEUZE, 1991, p.18). O liame da matéria é também com o tempo, pois é através dos fenômenos dele que descarrega a infinidade do organismo após se dividir em vários fragmentos. Ainda assim, a forma orgânica, pela física barroca, ao dobrar-se a si mesma em porções até que estas cheguem ao infinito, desdobra-se ao limite de desenvolvimento apropriado a cada ser. $\mathrm{O}$ exemplo do eu do poema parece mostrar mais ou menos, uma vez que ele percebe, meio inconsciente, esse fenômeno; daí a consciência no efêmero.

Ariano Suassuna, exercitando-se na poesia nos seus primeiros instantes de vida literária, já antecipava pelos versos as cores da arte armorial, que teria a heráldica da Idade Média campo junto à produção cultural sertaneja. Elevar a arte popular pelas mãos do erudito seria descobrir a arte brasileira, livrando-a do esmagador estado de vulgarização com o qual está envolvida nos dias atuais. Quando o Movimento Armorial foi lançado no Recife em outubro de 1970, Suassuna prestou esclarecimentos acerca das conexões desse tipo de estética, principalmente no que diz respeito à escolha do nome armorial. Argumenta o autor da trilogia A maravilhosa desaventura de Quaderna, o decifrador que optava pelo termo, a princípio pela beleza do próprio vocábulo e, em seguida, por sua influência heráldica. Para o paraibano, este modelo de representação da cultura de um povo está imerso nos emblemas dos ferros de marcar bois (Ariano, tempos depois, transformá-los-ia 
em letras do alfabeto sertanejo) ${ }^{1}$, nos estandartes das festividades de rua e nas bandeiras e uniformes de futebol das seleções esportivas do Brasil. Dessa maneira, no espírito popular se acomodaria com precisão à heráldica, herdada do contexto histórico da Europa dos tempos medievais e modernos:

Foi aí que, meio sério brincando, comecei a dizer que tal poema ou tal estandarte de Cavalhada era "armorial", isto é, brilhava em esmaltes puros, festivos, nítidos, metálicos e coloridos, como uma bandeira, um brasão ou um toque de clarim. Lembrei-me, aí, também das pedras armoriais dos portões e frontadas do Barroco brasileiro, e passei a estender o nome à Escultura com a qual sonhava o Nordeste. Descobri que o nome "armorial" servia, ainda, para qualificar os "cantares" do Romanceiro, os toques de viola e rabeca dos Cantadores - toques ásperos, arcaicos, acerados como gumes de faca-de-ponta da nossa Música barroca do Século XVIII. (SUASSUNA, 1979 apud NEWTON JÚNIOR, 1999, p.87)

Não é preciso mais nada após esse depoimento reproduzido aqui para reconhecerem-se as sombras do Barroco e do Simbolismo nas estrofes e versos suassunianos. O próprio escritor reforçaria esse dado em entrevista aos pesquisadores do Instituto Moreira Salles (2000, p.33). Mas além dos dois estilos de época especificados, seria negligência não acrescentar a poesia de Cordel os complementando na pulsação do verso. É inclusive muito usado o recurso das letras maiúsculas na literatura popular. Ao lado disso, é impossível esquecer as pinturas e os desenhos que acompanham o texto escrito, assim como no folheto de cordel, a famosa xilogravura. Sendo Ariano um artista plástico e cuidando da ilustração dos próprios poemas, não será por acaso e à toa que se deparará com essa técnica em Sonetos com Mote alheio e em Sonetos de Albano Cervonegro. Nos dois álbuns coloridos, as gravuras desenhadas por Suassuna, complementarão o sentido da temática do discurso poético, e mesmo o assunto daqueles poemas de inspiração barroca se enquadrará nesse círculo arturiano.

O que chama a atenção em todo o trabalho em poesia é a carga emblemática que está inserida nele. Isto é: as diversas insígnias representadoras dos mitos, lendas e estórias populares sertanejas, as quais aguçam o senso perceptivo do leitor. De qualquer maneira, entramos nas dobras da alma, que tocada pela fantasia do retrato místico do Sertão nordestino, precisa agora empregar seus artifícios em favor de uma explicação do espírito que só tem sua obscuridade diminuída graças à capacidade de o mesmo poder exigir um corpo. Nada mais é tal dedução que um julgamento moral do corpo. Contudo, outras teorias afirmam que nem tudo é obscuro na matéria, há também um lado claro. A clareza se institui das pequenas percepções. Estas só se arranjam em detrimento de minúsculas unidades que juntas perfazem a unidade maior, a dobra. São elas as mônadas. O universo não existe fora delas e dentro delas é infinito, sombrio. Os representantes ou os mais conhecidos "elementos atuais infinitamente pequenos" se combinam de micropercepções alucinatórias. Tudo se deve às inflexões diferentes de modo espontâneo. Nossas macropercepções conscientes, claras e precisas vão se modelar do conjunto de muitas pequenas percepções, confusas, obscuras que desequilibram uma macropercepção e organizam a seguinte. Certamente é o que se passa no exame do poema abaixo de Sonetos

\footnotetext{
${ }^{1}$ Cf. Ferros do Cariri: uma heráldica sertaneja (Recife: Guariba, 1974).
} 
de Albano Cervonegro (1985), o qual se baseia no Barroco para um maior aprofundamento:

\section{O CAMPO}

Tema do Barroco brasileiro

Um Sol-negro, de escuros Encrespados,

refletido nas Águas que matiza.

Alvas pedras. Amena e fresca Brisa.

Um fino Capitel transfigurado.

Pardos Montes, no Chão encastoados.

A Fonte. A crespa Relva, na divisa.

Colunas do frontal que o Musgo frisa.

$\mathrm{O}$ Vale que se fende, aveludado.

E o Pomar: seu odor, sua aspereza.

Essa Romã, fendida e sumarenta,

com o Topázio castanho, mal-exposto.

Os frutos adorantes. E a Beleza,

- esta Onça amarela que apascenta

a maciez da Morte e de seu gosto.

(SUASSUNA, 1999, p.203)

À medida que se vai percorrendo o olhar pelas estrofes, o percebido torna-se bem mais claro. $\mathrm{O}$ ambiente delineado aparenta estar em profunda mutação se comparado a um modo de vida estático. Ao mesmo tempo em que a Beleza põe o belo como sensação positiva ao espírito de quem contempla a paisagem, esconde o Feio em si mesma. Os montes, as insólitas pedras, a relva, a romã e o sol caloroso, que lhes vivifica, integram todo um ciclo vital, o qual termina sempre com a morte. Pela técnica com que as imagens foram organizadas, passa a ser simples perceber, por intermédio desse quadro simbólico e cíclico, as mônadas se constituindo, porquanto todos os artefatos de uma cena campestre alimentam o sonho do sublime até depois do fim da vida. Trata-se assim de um movimento alucinatório que justifica a razão do devir. A passagem das pequenas percepções do que é relatado para o estado consciente da percepção se dá com inquietude. É como se o inanimado de repente viesse a ser animado ou perfeitamente possível de ser compreendido. O problema de se viver no tempo barroco está no desafio de se conviver com certas relações diferenciais, ora desprezíveis, ora relevantes à mente. Ocorre esse fenômeno porque há uma relação de heterogeneidade nessas ações da natureza esboçadas na lírica suassuniana. Muitas delas se apresentam em demasia ao nosso senso perceptivo, capturando sua atenção; outras proporcionam pouco destaque e iludem nossos órgãos do sentido. Aí estão os desnivelamentos sensoriais. Até que se alcance a singularidade, a obra barroca precisa atravessar essa inconstância, na qual se observa a distinção entre dois 
fenômenos, e desse contraste chegar a uma terceira percepção sobre o mesmo fato. E paralelo a isso, existe uma nova dobra surgindo nesse ciclo vital da natureza pintado no soneto anterior, dando origem a nascentes dobras.

Em A mulher e o Reino, de Sonetos com mote alheio (1980), Suassuna volta ao mesmo tópico dessa vez incluindo na discussão um pouco do desejo pelo perigoso, isto é, a morte e o pecado de experimentá-lo como ao erótico. Se não, vejamos:

Ó Romã do pomar, Relva, esmeralda, olhos de Ouro e de azul - minha Alazã!

Ária em corda do Sol, fruto de prata, meu Chão e meu Anel — cor da Manhã!

Ó meu Sono, meu sangue, Dom, coragem, água das pedras, Rosa e belveder! Meu candieiro aceso da Miragem, meu mito e meu poder — minha Mulher!

Dizem que tudo passa e o Tempo duro tudo esfarela: o Sangue há de morrer! Mas quando a Luz me diz que esse Ouro puro

se acaba por finar e corromper, meu Sangue ferve contra a vã Razão e há de pulsar o Amor na escuridão! (SUASSUNA, 1999, p.193)

As projeções oníricas do poeta são tecidas pela combinação hermética: Pedras - Rosa Mulher - Tempo - Sangue - Razão - Amor. Numa mesma cadeia semântica ao lado da cadência rítmica dos versos, está outra seqüência; combinada de vocábulos de naturezas diversas (Luz - Ouro - Manhã — Miragem), pela qual também passeiam as mônadas no âmbito da nossa percepção singular. Mais uma vez o que se infere são relações diferenciais, já apontadas, selecionando as mínimas percepções até atingirem o nível do consciente. Às vezes, é de costume fazer o chamado cálculo diferencial nesses casos, pois essa ferramenta proposta por Leibniz, filósofo alemão, determina o mecanismo psíquico de cada percepção como se fosse um automatismo que ora mergulha no obscuro, ora no claro. Contudo, esse automatismo se dá de maneira universal e individual no texto de Suassuna. As relações diferenciais que ocorrem no organismo das mônadas se assemelham, embora esse dado possa parecer estranho a quem o comprova; e segundo, a mônada sofre atualização, pois que cada uma detém uma tonalidade diferente, em decorrência dessas diferenciações. Elas expressam o mesmo mundo, mas cada unidade tem sua própria zona clara, distinguidora de todas de modo geral. Com base em tal argumento, pode-se pôr em relevo que a percepção clara, pertencente a essa menor unidade da dobra, se ressalta pelo sentido do relevante, isto é, do percebido. Este, então, começa a obter singularidades.

Quais são os principais pontos de vista do singular nessa técnica empregada por Suassuna? Podemos colocar, a princípio, a inflexão que ocorre em função das linhas de universo e 
suas relações de distância. $\mathrm{O}$ arquétipo disso são as imagens díspares entre as idéias de desejo e poder em choque ao longo das estrofes. O ápice de tamanha singularidade pode ser visto no instante em que o sangue do eu-lírico desvenda o seu verdadeiro instinto frente à razão do mesmo. Os contrastes se enfrentam sem pudor no íntimo da voz que se pronuncia no texto. A singularidade desse Reino desejado qual uma fêmea pelo macho é o prélio pelo resgate do que fora esquecido pelo poeta em algum lugar do passado. Sua memória parece permanecer latente até tornar-se relevante a quem contempla. E nesse turbilhão de conexões de diferenciação é que se organiza a zona clara das mônadas. A partir daí, as distinguimos umas das outras, tais quais as pulsões de vida que o eu sofre na procura pelo paraíso perdido, soterrado, e toda a sua sensibilidade sedutora.

\section{CONCLUSÃO}

Fica mais ou menos clara a definição acerca das dobras como artefatos do barroquismo dos Setecentos, da mesma forma que as suas proporções e desproporções feitas a fim de se abranger uma singularidade. Do singular descobriu-se a sua composição: as mônadas, pequenas unidades. $\mathrm{O}$ senso perceptivo abraça certas percepções, que averiguam a vida própria da dobra, em micropercepções e macropercepções, sempre as primeiras se juntando para corporificar as segundas. Também é palpável o efeito alucinatório que se esconde por esse fenômeno caracterizador do Barroco, uma arte de detalhes. O mais certo é atentarmos, sempre que possível, para até que limite vai o percebido e as vibrações que ele captura para servir ao nosso olhar. Aí está a heterogeneidade da escrita perfeitamente aplicada à multiface suassuniana.

\section{REFERÊNCIAS BIBLIOGRÁFICAS}

DELEUZE, Gilles. A dobra: Leibiniz e o Barroco. Trad. Luiz B. L. Orlandi. Campinas: São Paulo: Papirus, 1991.

HATZFELD, Helmut Anthony. Estudos sobre o Barroco. Trad. Célia Berretini. São Paulo: Perspectiva, 1998. (Stylus; 8)

NEWTON JÚNIOR, Carlos. O pai, o exílio e o reino: a poesia armorial de Ariano Suassuna. Recife: EDUFPE, 1999.

SUASSUNA, Ariano. Poemas: seleção, organização e notas de Carlos Newton Júnior. Recife: EDUFPE, 1999.

Ao sol da prosa brasiliana. In: Cadernos de Literatura Brasileira. São Paulo, n.10. p. 23 - 51, nov.2000. Entrevistadores: Editores dos Cadernos. 